\title{
A Multistage Technique for Examination Timetabling
}

\author{
B. Hemalatha \\ Administrative Computer \\ Service Support Center \\ IIT Kharagpur, India
}

\begin{abstract}
Scheduling examinations in a large academic institution is a complicated and time consuming task. Though, there is a large volume of research in the area of examination scheduling a huge gap between theory and practice exists. Each institution has its own academic set up and specific constraints, that a general method or algorithm that works for one system may not produce the desired result for the other. In this paper a multistage technique that is in successful use for scheduling examinations at IIT Kharagpur is elaborated. The method partitions the examination data into a three sets, each of which is scheduled independently. The first part comprises a set of subjects for which the soft constraint compliance has a high priority. The second stage involves the isolation of subject sets that can be scheduled independently followed by the third stage that schedules remaining subjects based on the lecture schedules and the final stage fine tunes the timetable to satisfy soft constraints. .
\end{abstract}

\section{General Terms}

Examination Timetabling

\section{Keywords}

Multistage Technique, Hard Constraints, Soft Constraints, Subject Time Table Slots, Optimal Time Table

\section{INTRODUCTION}

In a system that is increasingly student centric, universities and higher education institutions face an uphill task of drawing up an examination schedule that satisfies all stakeholders. A poorly scheduled examination time table adversely effects the academic outcomes. Examination Time Tabling is essentially an optimization problem where a set of conditions called as 'Hard Constraints' must and should be rigidly enforced at all times while another set of conditions called the 'Soft constraints' must be satisfied to a large degree to obtain a good quality schedule. The set of hard and soft constraints is Institution specific.

Traditionally in literature, examination scheduling forms a part of educational time tabling. Over the past decade a considerable amount of research on examination timetabling has been reported in literature. Kristiansen, S and Stidsen [1] provide an in depth survey of literature in educational time tabling. Two major global conferences on scheduling, namely Practice and theory of Automated Timetable(PATAT) [2] and Multidiscplinary International Scheduling Conference-Theory \& Applications (MISTA) [3] held every two years have sessions and competitions dedicated to the area of educational timetabling that include university class and exam timetabling problems. Qu et al [4] give an excellent summary of the various approaches and algorithms that have been attempted to solve the exam time tabling problem. A recent article in PATAT 2016 [5] traces the chronology of developments in the area of educational time tabling from the 80s till recent date The algorithm side has seen the use of Graph Coloring, Heuristics, Meta-Heuristics, Swarm Optimization, Genetic Algorithms ,evolutionary algorithms and Tabu Search methods in search of a global solution. $[1,4,5]$ give an exhaustive set of references on these methods. These approaches tend to optimize and obtain a feasible solution for a set of constraints. On the application side, there are software packages that integrate the algorithms leading to automated time table generation. The UniTime software [6,7] developed by Purdue university for comprehensive educational scheduling system integrates a 'Time Table solver' for generating course and exam timetables. MIT recently adopted the UniTime system for course and exam timetabling [8]. A software based on an intelligent multiagent system for examination timetabling has been reported [9].

This paper describes a multistage technique, that is specific to the academic setup and constraints at IIT Kharagpur, for scheduling the examinations.

\section{EXAMINATION SCHEDULE}

IIT Kharagpur follows a semester system and conducts two examinations, mid and end every semester. In most cases the schedules for both the mid and end examinations are identical as the enrolment profile and number of examination sessions remain the same. The examination schedule is prepared after all the student enrolments are complete. The dates of the examination are decided well in advance by the Senate and it is mandatory to conduct all the exams within the time frame specified. Typically the exams are held in 14 sessions over a period of 7 days, with each day having 2 sessions of equal duration, in the morning and afternoon. On an average in a particular academic session, there are 700 subjects with 45000 enrolments.

\subsection{Enrolment Profile}

The enrolment profile is the basis for exam scheduling. A course based curriculum is followed for the Under graduate and Post graduate programs of the Institute. The students at each level are expected to take a fixed number of courses each semester. The courses normally comprise of a rigid part and a flexible part, where the student is free to take a course of his choice subject to timetable constraints. Variations in the enrolled subjects for a student set at a particular level of study, occurs due to the flexible components and optional components. Under the optional component, a student can register for additional subjects. Figure 1 shows the components of the enrolment record of a student. Depending upon the academic status and the level of study of the student, the enrolment record may contain some or all the components for a particular student. 


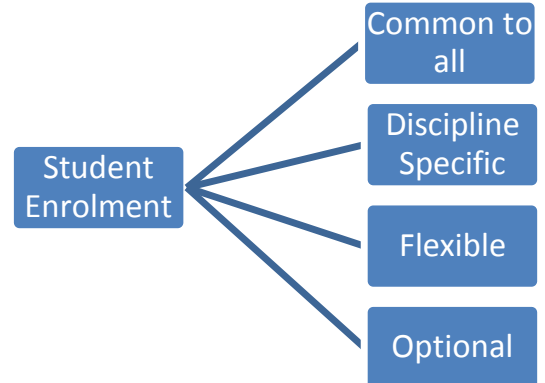

Figure 1 Components of Student Enrolment

Each subject is equally available to all students in the form of flexible or optional components. An important subset of the total enrolment record is that of the first year undergraduate students who constitute $25 \%$ of the total students and have only common compulsory subjects. The total enrolment profile, thus exhibits a high degree of subject interdependency that make the process of exam scheduling in a fixed time frame very challenging.

\subsection{The Subject Time Slots}

The subject time table is an important component of student enrolment and consequently the exam scheduling. The schedules of all subjects are fixed before the process of enrolment. Student enrolment for subjects is strictly on the basis of these time schedules, thus, no student is allowed to enrol for two or more subjects that have overlapping lecture hours.

Majority of the subjects, be it common, specific or flexible have 3 or 4 contact hours. There are few special subjects that have 2 contact hours. IIT Kharagpur has evolved a unique slot based Time Table matrix for lecture scheduling, shown in Figure 2. Each time table slot has standard meeting patterns within the five days of a week and official class hours. There are $2 \mathrm{hr}, 3 \mathrm{hr}$ and $4 \mathrm{hr}$ slots which are used for scheduling classes of subjects of having 2,3 and 4 contact hours respectively. A $4 \mathrm{hr}$ slot can also be used by a $3 / 2$ contact hour course. Similarly any 2 hours of a 3 hour slot can be used for a 2 hour contact course. The classes of all subjects in a semester are scheduled in complete conformity with the time tabling slotting pattern. Cross slotting is not permitted. As seen from Figure 2 there are 14 distinct non overlapping time table slots designated as \{A3,B3,C4,D4,E4,F4,G3,H3,I2,S3,U4,X2,Y2\}. The number suffixed to the alphabet indicates the total number of contact hours of the slot.

A-G are morning slots, where most of the lecture classes are held. A few specialized courses have their classes in the afternoon slots that range from $\mathrm{H}-\mathrm{Y}$. Barring the subjects of first year, any subject at the higher level that has multiple sections has an identical time schedule across the sections. Each of the first year subjects are offered in different time slots for different sections. A student at higher level of study can enroll for subjects of previous levels depending on the availability of time table slots. As no student can enroll for two or more subjects that are in the same time table slot, scheduling examinations of all subjects (except first year subjects) in a particular time slot in a session ensures that hard constraint of direct student conflict is immediately satisfied.

\begin{tabular}{|c|c|c|c|c|c|c|c|c|c|}
\hline $\begin{array}{c}\text { Perio } \\
d\end{array}$ & 1 & 2 & 3 & 4 & 5 & 6 & 7 & 8 & 9 \\
\hline $\begin{array}{c}\text { MO } \\
\mathrm{N}\end{array}$ & \multicolumn{2}{|c|}{$\mathrm{A} 3(1,2)$} & $\begin{array}{c}\mathrm{C} 4(1 \\
)\end{array}$ & $\begin{array}{c}\text { B3(1 } \\
\text { ) }\end{array}$ & $\begin{array}{c}\text { D4(1 } \\
\text { ) }\end{array}$ & $\begin{array}{c}\mathrm{H} 3(1 \\
)\end{array}$ & \multicolumn{2}{|c|}{$\mathrm{U} 4(1,2)$} & $\begin{array}{c}\text { S3(1) } \\
\text { (1) }\end{array}$ \\
\hline TUE & & & & & $\begin{array}{c}\text { A3(3 } \\
\text { ) }\end{array}$ & \multicolumn{2}{|c|}{$\mathrm{U} 4(3,4)$} & \multicolumn{2}{|c|}{$\mathrm{H} 3(2,3)$} \\
\hline $\begin{array}{c}\text { WE } \\
D\end{array}$ & \multicolumn{2}{|c|}{$\mathrm{C} 4(2,3)$} & $\begin{array}{c}F 4(1 \\
)\end{array}$ & $\begin{array}{c}\text { G3(1 } \\
\text { ) }\end{array}$ & $\begin{array}{c}\text { E4(1 } \\
\text { ) }\end{array}$ & \multicolumn{2}{|c|}{$X 2(1,2)$} & \multicolumn{2}{|c|}{$Y 2(1,2)$} \\
\hline THU & $\begin{array}{c}\text { D4(4 } \\
\text { ) }\end{array}$ & $\begin{array}{l}\text { F4( } \\
\text { 2) }\end{array}$ & $\begin{array}{c}\text { C4(4 } \\
)\end{array}$ & $\begin{array}{c}E 4(2 \\
)\end{array}$ & $\begin{array}{c}\mathrm{G} 3(2 \\
)\end{array}$ & $12(1)$ & \multicolumn{2}{|c|}{ V4(1,2) } & $\begin{array}{c}\text { S3(2 } \\
\text { ) }\end{array}$ \\
\hline FRI & $\begin{array}{c}\mathrm{G} 3(3 \\
)\end{array}$ & \multicolumn{2}{|c|}{$E 4(3,4)$} & \multicolumn{2}{|c|}{$F 4(3,4)$} & \multicolumn{2}{|c|}{ V4 $(3,4)$} & $\begin{array}{c}12(2 \\
1\end{array}$ & $\begin{array}{c}\text { S3(3 } \\
\text { ) }\end{array}$ \\
\hline
\end{tabular}

Figure 2 -Time Tabling Slot Pattern

\section{PROBLEM DEFINITION}

The task is thus to schedule the exams in the given time frame with the following constraints:

\section{Hard Constraints}

1. The exams of all theory subjects must be scheduled in 14 sessions that comprise 7 days with each day having 2 sessions of equal duration.

2. Each subject has only one exam, even if there are multiple sections. No exam can be split across sessions.

3. No student must have two examinations in the same session. Direct student conflicts are not allowed. The first year common subjects must have a day's gap and must be scheduled in the morning.

4. Number of students having two consecutive exams on the same day must be minimum.

5. Preferable not to have two core/compulsory subjects of a discipline at a particular level of study on the same day.

As the infrastructure availability is sufficient there are no constraints placed on the room resources. Additionally, constraints are also not placed on the proctor resources. Occasionally there are instructor or student preferences for conducting the examinations on a particular day. Thus, the main problem is to schedule the subjects only

\section{SOLUTION METHODOLOGY}

\subsection{Database Representation}

The complete student enrolment data along with the time table slots and details of examination sessions are maintained in a database using simple tables as shown in Figure 3. The details of the structures are:

Enrolment Profile \{stuid, subid, tt_slot, comp, enrol_type The field 'Comp'-refers to the components mentioned in Figure 1 and enrol_type indicates whether it is regular or a backlog registration. 


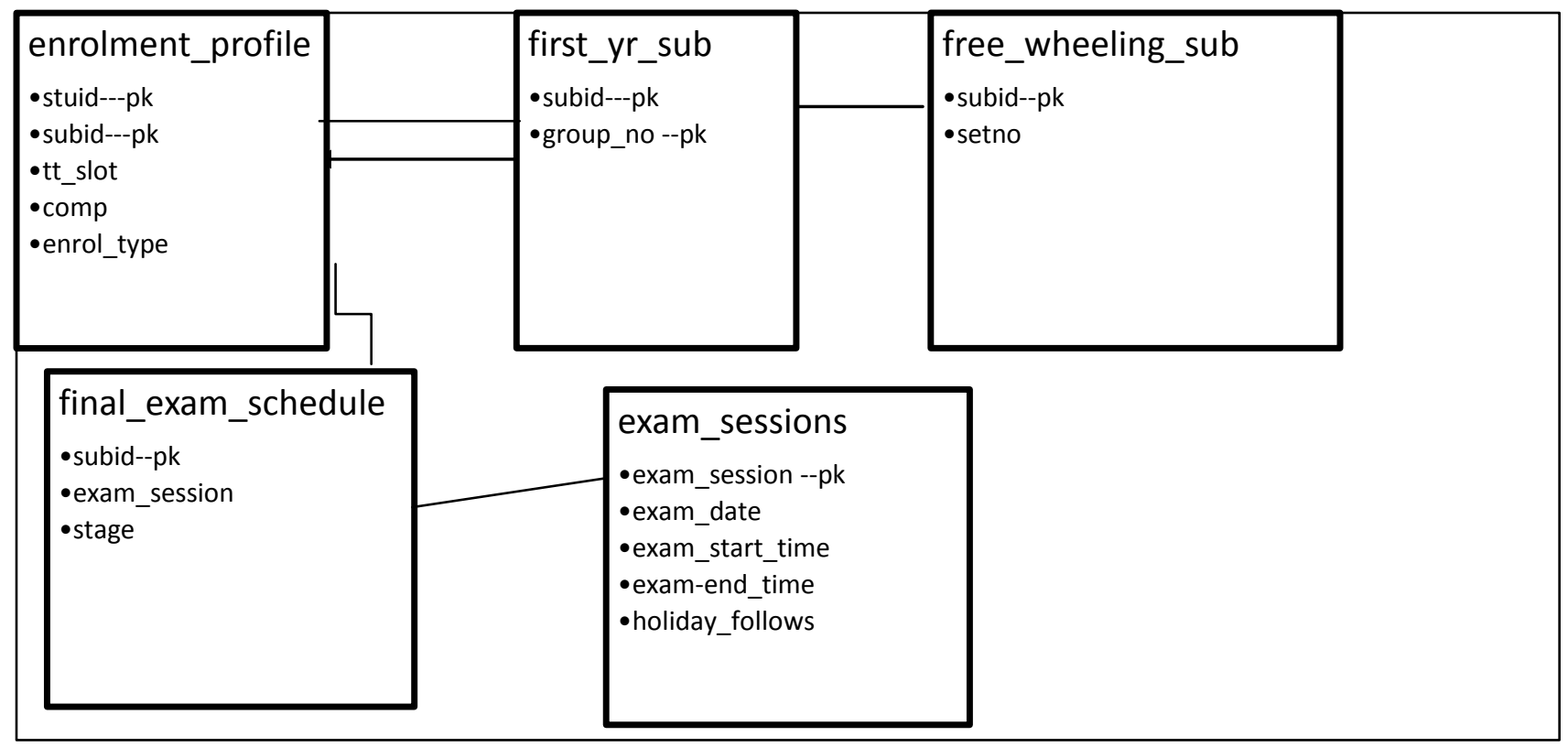

Figure 3 Database Representation

\begin{abstract}
Exam Sessions \{exam_session , exam_date, exam_start_time, exam_end_time, holiday_follows
\end{abstract}

The exam sessions are designated as ES1, ES2, ES3...ES14. The sessions with odd numbers are morning sessions and those with even numbers are afternoon sessions. The field 'holiday follows' indicates if the next day is a holiday.

First_yr_sub \{subid, group_no\}, contains the first year subjects. The significance of group_no is explained in the subsequent section.

Free_wheeling_sub \{subid, setno\} contains the sets of subjects that can be scheduled independently. This table is populated using the method described in the subsequent section.

Final_Exam_schedule \{subid, exam_session, stage $\}$ has the final exam schedule and the field 'stage' denotes the stage of the program where it was scheduled.

\subsection{Methodology}

From the enrolment profile, the data is segregated into 3 parts. The first part is the set of common subjects taken by the first year students, for whom the soft constraints compliance is a high priority, the second part comprises sets of subjects that can be scheduled independently and the third portion comprises of the remaining subjects. The following approach is adopted:
1. The first part of the data that contains common first year subjects are readily available in the database. These subjects are scheduled in such a way that there is only one exam per day in the morning and there is a day's gap between two exams.

2. In the second part, an interdependency matrix that indicates the number of dependent subjects for each subject is constructed. From this matrix the set of subjects that have dependency only on its members are isolated and are scheduled to satisfy as many soft constraints that may be imposed. These sets are termed as free wheeling components.

3. After isolating part 1 and part 2 the remaining subjects are scheduled on the basis of subject slots. Subjects in Time Table slots A-G are fitted in the vacant after noon examination sessions. The subjects of the other slots H-Y are scheduled in the morning along with the first year subjects in such a way that the hard constraints are satisfied.

4. The time table is then fine tuned by moving/swapping the after noon exam sessions in such a way as to minimize the number of students taking two exams on the same day.

5. The steps of the process is shown in Figure 4. 


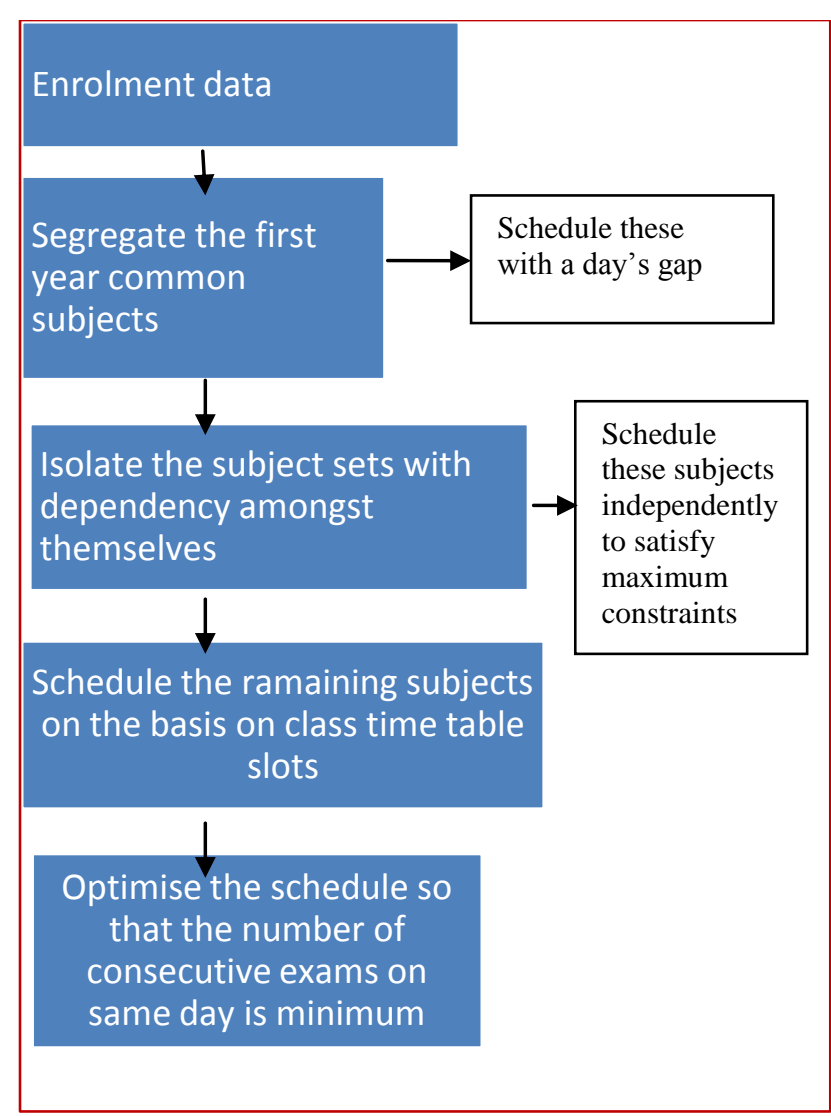

Figure 4 Representation of various stages of scheduling

\subsection{First Stage-Common Subjects}

First year students are divided into 2 groups. There are 7 first year lecture subjects. Of the 7 subjects one subject is common to both groups and three subjects each are taken by Group 1 and Group 2 respectively in a particular semester and swapped for the subsequent one. The subjects are classified as hard /soft subjects. Soft subjects need not have a day's gap. In the current set only one soft subject exists. The common subjects are taught in multiple sections, each section has a different time table slot. Ideally, except for the common subject, no student overlap should exist between Group 1 \& Group 2 . However, overlap between the 2 groups is caused by students from higher years enrolling for the subjects from both groups. Thus in most cases it is not possible to schedule the subjects of Group1 and Group 2 simultaneously. The exam sessions for the first year subjects are now fixed as per the soft constraints specified in section 3, with each of the 7 subjects scheduled on each day morning. The common subject is scheduled on the first day. This stage can thus be looked upon as unconstrained scheduling. A typical first year schedule is shown in Table-1.

\section{Table -1 -A typical First Year Schedule}

\begin{tabular}{|l|l|l|l|l|l|l|}
\hline ES1 & ES3 & ES5 & ES7 & ES9 & ES11 & ES13 \\
\hline \multicolumn{7}{|l|}{ Assuming no break day between ES1 \& ES3 } \\
\hline C & G21(s) & G11 & G22 & G12 & G23 & G13 \\
\hline \multicolumn{7}{|l|}{ Assuming break day between ES1 \& ES3 } \\
\hline C & G22 & G11 & G21(s) & G12 & G23 & G13 \\
\hline
\end{tabular}

$\mathrm{C}$ is the common subject, G11,G12,G13 represent the three subjects in Group1. Similarly G21,G22,G23 represent the three subjects in Group2. (s) indicates that it is a soft subject. The exam sessions thus fixed are not altered in the subsequent stages.

\subsection{Second Stage -Isolation of Free Wheeling Subjects}

In this stage, the sets of subjects that have interdependency only amongst their members - termed as the free wheeling components are isolated. The first step in identifying such sets is to form the subject intersection matrix.

Intersection Matrix- Let $S_{1}, S_{2}, S_{3} \ldots S_{n}$ be the $n$ subjects for which the schedule has to be drawn up. $X_{m n}$ denote the number of students who are taking both subjects $m \& n$. The intersection matrix is represented as shown in Table 2

Table -2 Intersection Matrix

\begin{tabular}{|c|c|c|c|c|c|}
\hline Subjects & $\mathrm{S}_{1}$ & $\mathrm{~S}_{2}$ & $\mathrm{~S}_{3}$ & $\mathrm{~S}_{\mathrm{m}}$ & $\mathrm{S}_{\mathrm{n}}$ \\
\hline $\mathrm{S}_{1}$ & $\mathrm{X}_{11}$ & $\mathrm{X}_{12}$ & $\mathrm{X}_{13}$ & $\mathrm{X}_{1 \mathrm{~m}}$ & $\mathrm{X}_{1 \mathrm{n}}$ \\
\hline $\mathrm{S}_{2}$ & $\mathrm{X}_{21}$ & $\mathrm{X}_{22}$ & $\mathrm{X}_{23}$ & $\mathrm{X}_{2 \mathrm{~m}}$ & $\mathrm{X}_{2 \mathrm{n}}$ \\
\hline $\mathrm{S}_{3}$ & $\mathrm{X}_{31}$ & $\mathrm{X}_{32}$ & $\mathrm{X}_{33}$ & $\mathrm{X}_{3 \mathrm{~m}}$ & $\mathrm{X}_{3 \mathrm{n}}$ \\
\hline $\mathrm{S}_{\mathrm{m}}$ & $\mathrm{X}_{\mathrm{m} 1}$ & $\mathrm{X}_{\mathrm{m} 2}$ & $\mathrm{X}_{\mathrm{m} 3}$ & $\mathrm{X}_{\mathrm{mm}}$ & $\mathrm{X}_{\mathrm{mn}}$ \\
\hline $\mathrm{S}_{\mathrm{n}}$ & $\mathrm{X}_{\mathrm{n} 1}$ & $\mathrm{X}_{\mathrm{n} 2}$ & $\mathrm{X}_{\mathrm{n} 3}$ & $\mathrm{X}_{\mathrm{nm}}$ & $\mathrm{X}_{\mathrm{nn}}$ \\
\hline $\mathrm{X}_{12}=\mathrm{X}_{21}, \mathrm{X}_{23}=\mathrm{X}_{32,} \mathrm{X}_{\mathrm{mn}}=\mathrm{X}_{\mathrm{nm}}, \quad$ and so on.
\end{tabular}

Dependency Pattern: From this a dependency pattern for each subject is obtained by concatenating the subject and corresponding strength as follows:

Patt-S $_{1}=\{\mathrm{S} 1-\mathrm{X} 11, \mathrm{~S} 2-\mathrm{X} 12, \mathrm{~S} 3-\mathrm{X} 13 \ldots \mathrm{Sn}-\mathrm{X} 1 \mathrm{n}\}$

only those dependent subjects where the strength is greater than 0 is considered. All the subjects with the pattern are arranged in ascending order. This means for any subject, the dependency pattern at once indicates the associated subjects along with the intersecting student strength. This also implies that no subject in the string can be scheduled along with the subject in column 1 to avoid a direct student conflict.

Interdependency Matrix With these values, a subject interdependency matrix, that has three columns is constructed. The first column is the subject and the second column is the dependency pattern, having overlapping subjects along enrolments. The third column is a number denoting the number of subjects that can not be scheduled with that in column 1 . This is the length of the dependency pattern string array. From the dependency patterns it is easy to identify and isolate the subject sets that are wholly taken by one student set only. These sets can be easily identified as those subjects which have similar intersection pattern. This implies that these students are enrolled only for the subjects in the pattern and more importantly no other student external to this set has enrolled for these subjects. . Normally each such set has a maximum of 6 or 7 subjects and they constitute a set of core subjects from a specialized discipline. An example from a real time data set is given in Table 3

Table -3 Interdependency Matrix

\begin{tabular}{|l|l|r|}
\hline Subid & Pattern & $\begin{array}{r}\text { No of } \\
\text { Subjects }\end{array}$ \\
\hline BS40003 & $\begin{array}{l}\{\text { BS40003-11,BS40005-11,BS40009- } \\
11, \mathrm{BS} 41001-11, \mathrm{BS} 41003-11, \mathrm{BS} 41005-11\}\end{array}$ & 6 \\
\hline BS40005 & $\{$ BS40003-11,BS40005-11,BS40009- & 6 \\
\hline
\end{tabular}




\begin{tabular}{|l|l|r|}
\hline & $11, \mathrm{BS} 41001-11, \mathrm{BS} 41003-11, \mathrm{BS} 41005-11\}$ & \\
\hline \multirow{2}{*}{ BS40009 } & $\begin{array}{l}\{\mathrm{BS} 40003-11, \mathrm{BS} 40005-11, \mathrm{BS} 40009- \\
11, \mathrm{BS} 41001-11, \mathrm{BS} 41003-11, \mathrm{BS} 41005-11\}\end{array}$ & 6 \\
\hline BS41001 & $\begin{array}{l}\{\mathrm{BS} 40003-11, \mathrm{BS} 40005-11, \mathrm{BS} 40009- \\
11, \mathrm{BS} 41001-11, \mathrm{BS} 41003-11, \mathrm{BS} 41005-11\}\end{array}$ & 6 \\
\hline BS41003 & $\begin{array}{l}\{\mathrm{BS} 40003-11, \mathrm{BS} 40005-11, \mathrm{BS} 40009- \\
11, \mathrm{BS} 41001-11, \mathrm{BS} 41003-11, \mathrm{BS} 41005-11\}\end{array}$ & 6 \\
\hline BS41005 & $\begin{array}{l}\{\mathrm{BS} 40003-11, \mathrm{BS} 40005-11, \mathrm{BS} 40009- \\
11, \mathrm{BS} 41001-11, \mathrm{BS} 41003-11, \mathrm{BS} 41005-11\}\end{array}$ & 6 \\
\hline BS50001 & $\{\mathrm{BS} 50001-5, \mathrm{BS} 50005-5, \mathrm{BS} 50007-5\}$ & 3 \\
\hline BS50005 & $\{\mathrm{BS} 50001-5, \mathrm{BS} 50005-5, \mathrm{BS} 50007-5\}$ & 3 \\
\hline BS50007 & $\{\mathrm{BS} 50001-5, \mathrm{BS} 50005-5, \mathrm{BS} 50007-5\}$ & 3 \\
\hline
\end{tabular}

It is seen that set 1 has 6 subjects each of which have a similar pattern, indicating that these subjects are taken only by a set of 11 students. Similarly set 2 has 3 subjects. To cross check and confirm, the student strength is expanded in terms of the actual student ids to ensure similarity. These sets are now transferred to the relation free wheeling subjects and each set is scheduled independently to satisfy as many soft constraints as possible.

\subsection{Third Stage of Scheduling}

After segregating and scheduling subjects in the first two stages, the remaining subjects (which constitute a major portion) are scheduled on the basis of time table slots. All the lecture classes are scheduled in complete conformity with the time tabling slotting pattern. The time table slots for all subjects are available and no student is allowed to take two or more subjects in the same slot, be it part or whole. This fact ensures that the hard constraint of a direct student conflict is immediately satisfied when all subjects of a time table slot are placed in a particular examination session.

With the first year subjects scheduled in the morning, subjects in the time table slots from A-G are scheduled in the afternoon examination session. Slot from A-G are considered because majority of the subjects are offered in these slots. In the initial phase, the subjects of the time table slots are randomly assigned in the afternoon session. As mentioned earlier, that subjects in stage 3, will have an overlap with first year subjects, thus the subjects schedule in slots H-Y (are placed along with first year subjects in the morning so as to satisfy the hard constraints. Table -4 indicates an initial solution for the third stage:

Table -4 Initial Solution for Stage 3 Scheduling

\begin{tabular}{|l|l|}
\hline $\begin{array}{l}\text { Morning } \\
\text { Session }\end{array}$ & $\begin{array}{l}\text { Afternoon } \\
\text { H-ES1 }\end{array}$ \\
\hline A-ES3 & B-ES4 \\
\hline U-ES5 & C-ES6 \\
\hline V-ES7 & D-ES8 \\
\hline S-ES9 & E-ES10 \\
\hline X-ES11 & F-ES12 \\
\hline Y-ES13 & G-ES14 \\
\hline
\end{tabular}

It must be mentioned that only a few specialized courses have their classes in the afternoon slots. With this all subjects for which the examination has to be conducted are scheduled. The time table is now fine tuned as described in the next session to obtain an optimal solution.

\subsection{Fine Tuning the Time Table}

To fine tune the schedule, the number of students having two consecutive examinations (called as neighbours) on the same day is minimized. In order to achieve this, the number of neighbours for all combinations by keeping the morning sessions fixed, with the initial solution as the starting point, is computed. It must be noted that the set of subjects which have been scheduled on the basis of Time Table slots can be moved/swapped with another set scheduled as the hard constraints are automatically satisfied for all the members of each set. The initial placements in the afternoon sessions are swapped so as to achieve a minimum. The example in Table 5 illustrates the process:

Table 5. Neighbor Computation

\begin{tabular}{|l|l|l|}
\hline $\begin{array}{l}\text { Morning } \\
\text { Exam Session }\end{array}$ & $\begin{array}{l}\text { Afternoon } \\
\text { Exam Session }\end{array}$ & $\begin{array}{l}\text { Total } \\
\text { neighbors }\end{array}$ \\
\hline ES1 & ES2 & 100 \\
\hline ES1 & ES4 & 50 \\
\hline ES3 & ES2 & 25 \\
\hline ES3 & ES4 & 200 \\
\hline ES5 & ES2 & 280 \\
\hline ES5 & ES4 & 100 \\
\hline ES5 & ES6 & 103 \\
\hline
\end{tabular}

From the above it is seen that ES4 \& ES2 can be swapped. The subjects of the Time Table slots are placed so as to yield the best combination that has minimum number of students having consecutive exams on the same day. Since the core subjects are normally placed in slot A-G, the soft constraint of minimizing two core subjects on the same day is also met with.

\subsection{Exam Time Table Application}

The software application that was initially developed in Sybase/ASP.NET interface is now migrated to PostgreSQL and JAVA/JSP interface. Based on the logic detailed above the software generates automatic time tables. An interactive interface is also available to edit, change and modify. The data for all stages are extracted from the database through simple SQL queries/functions.

This method has been successfully used for over a decade scheduling 650-700 subjects with about 45000-50000 enrolments each semester

\subsection{Typical Results}

For the academic session in Autumn 2018-2019:

Number of students taking examination: $\mathbf{8 6 0 8}$

Total enrolment (for theory subjects only):40609

Disciplines: 88 UG Disciplines, 66 PG Disciplines

Number of theory subjects for which exam is scheduled: $\mathbf{7 3 8}$

Number of Exam Sessions: 14

Number of Subjects in Stage 1: 7

Number of Subject Sets in Stage 2: 4 
Set pattern for Stage $2:\{1(3), 2(6), 3(6), 4(8)\}$

Number of Subjects for Stage 3: 708

Number of Direct Conflicts: 0

Figures 5 and 6 show the distribution of the subjects and number of students over the 14 exam sessions respectively

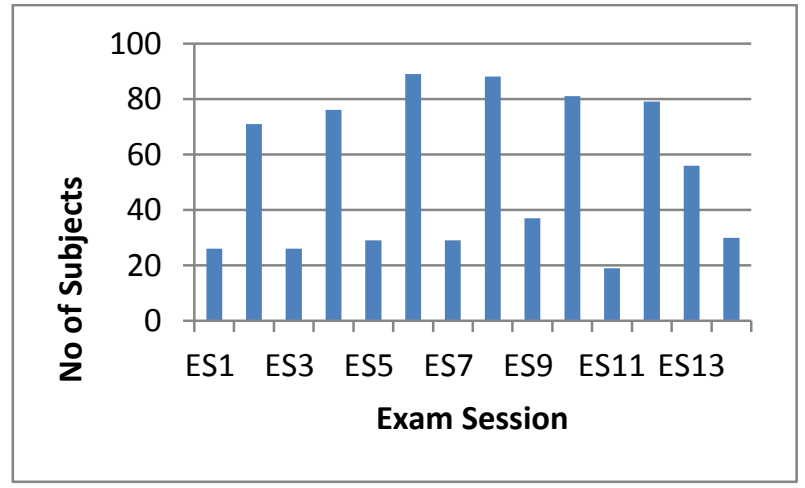

Figure 5 Distribution of Subjects across exam sessions

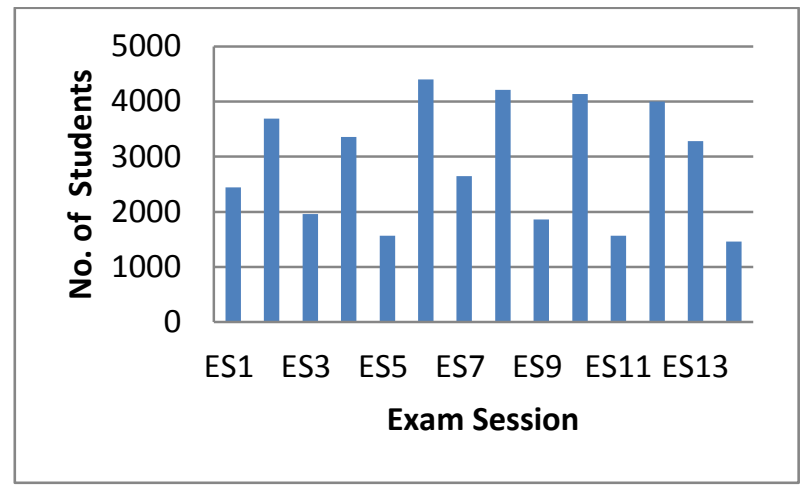

Figure 6 Number of students across exam sessions

Table -6 presents the number and hence the percentage of total students having two exams on the same day.

Table -6 Number of Students having Consecutive exams in a day

\begin{tabular}{|c|c|c|c|c|c|c|}
\hline \multirow[b]{2}{*}{ Day } & \multirow{2}{*}{$\begin{array}{c}\text { Morning } \\
\text { Session }\end{array}$} & \multirow{2}{*}{$\begin{array}{c}\text { Afternoon } \\
\text { Session }\end{array}$} & \multicolumn{2}{|c|}{ Overall } & \multicolumn{2}{|c|}{$\begin{array}{l}\text { Core } \\
\text { Only }\end{array}$} \\
\hline & & & No. & $\%$ & No. & $\%$ \\
\hline 1 & ES1* & ES2 & 161 & 1.87 & 28 & 0.33 \\
\hline 2 & ES3 & ES4 & 467 & 5.43 & 189 & 2.2 \\
\hline 3 & ES5 & ES6 & 266 & 3.09 & 154 & 1.79 \\
\hline 4 & ES7 & ES8 & 383 & 4.45 & 101 & 1.17 \\
\hline 5 & ES9 & ES10 & 283 & 3.29 & 30 & 0.35 \\
\hline 6 & ES11* & ES12 & 815 & 9.47 & 656 & 7.62 \\
\hline 7 & ES13 & ES14 & 327 & 3.8 & 168 & 1.95 \\
\hline
\end{tabular}

* indicates a break day follows

Overall - Number of students (along with percentage of total students) having 2 consecutive exams on the same day
Core Only - Out of the overall, number of students along with the percent values, having two consecutive core courses.

It is seen that even in the worst case scenario, which is on day 6 corresponding to examination session 11 and 12, less than $10 \%$ of the students have two consecutive exams in a day. In all the other cases less than $5 \%$ of students have two consecutive exams on the same day, the corresponding value is $1-2 \%$ for the back to back core subjects.

\section{CONCLUSIONS}

This paper details a multistage technique for scheduling examinations. The method is specific to the academic setup and constraints imposed at IIT Kharagpur. The procedure is based on partitioning the data into three distinct parts, the first part performs a unconstrained scheduling to set of subjects where the soft constraint compliance is a high priority. The second part isolates sets of subjects that have dependency only amongst its members and schedules them independently to satisfy as many soft constraints. The third part which constitutes a major chunk is scheduled on the basis of time table slots of the subjects. The final stage fine tunes the time table to reduce the number of students having 2 consecutive exams in a day.

As the major part of scheduling is based on the subject time table slots, the hard constraint of a direct conflict is immediately solved. This is one of the biggest advantage of the method. Identifying and isolating the subject sets that have dependency only on its members is another unique feature of the method. The method is in successful use at the Institute.

\section{ACKNOWLEDGMENTS}

The author thanks IIT Kharagpur for providing an opportunity to work on the problem.

\section{REFERENCES}

[1] Kristiansen, S., \& Stidsen, T. R. (2013). A Comprehensive Study of Educational Timetabling - a Survey. Department of Management Engineering, Technical University of Denmark. DTU Management Engineering Report, No. 8.2013. Web Link: http://orbit.dtu.dk/files/60366101/A_Comprehensive_Stu dy.pdf

[2] Conference on Practice anf Theory of Automated Time Tabling (PATAT). Web Linkhttp://patatconference.org

[3] Multidsiciplinary International Scheduling Conference Theory \& Applications, (MISTA) Web Link http://www.schedulingconference.org/

[4] Sannella, Qu, R., Burke, E. K., McCollum, B., Merlot, L. T., \& Lee, S. Y. (2009). A survey of search methodologies and automated system development for examination timetabling. Journal of scheduling, 12(1), 55-89. Web Link http://www.cs.nott.ac.uk/ pszrq/files/Exam_Review

[5] Rudy A. Oude Vrielink, Daniel Schepers, Erik A. Jansen- Practices in Timetabling in Higher Education Institutions ,PATAT 2016, Web Link http://patatconference.org/patat2016/files/proceedings/pa per_24.pdf

[6] University Time Tabling, Comprehensive Academic Scheduling Solutions, Unitime Software, Web link https://www.unitime.org/ 
[7] T. Müller, 'Constraint-based Timetabling' Ph.D. Thesis, 2005 KTIML MFF UK, Prague. Web Link https://www.unitime.org/papers/phd05.pdf

[8] Improving MIT's scheduling system, MIT News, Web Link http://news.mit.edu/2015/unitime-improving-mitscheduling-system-0122
[9] Nicholas Oluwole Ogini, Noah Oghenefego Ogwara and Obeten Obi Ekabua. Intelligent based Multi-Agent Approach for University Timetable Scheduling System. International Journal of Computer Applications 182(1):10-21, July 2018. Web Link https://www.ijcaonline.org/archives/volume182/number1 /ogini-2018-ijca-917432.pdf 